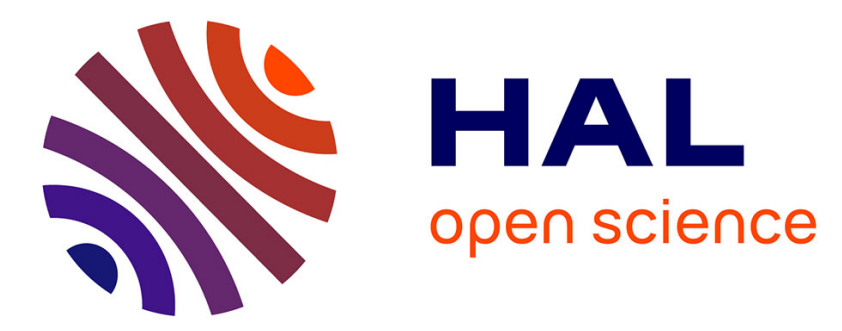

\title{
Studying the Rerouting of Empty Carriers during their Return Trips to Manage Rare Mobile Resources in a Physical Internet
}

\author{
Moustafa Nakechbandi, Jean-Yves Colin
}

\section{To cite this version:}

Moustafa Nakechbandi, Jean-Yves Colin. Studying the Rerouting of Empty Carriers during their Return Trips to Manage Rare Mobile Resources in a Physical Internet. GOL'20, The 5th. IEEE International Conference on Logistics Operations Management, Oct 2020, Rabat (virtual), Morocco. 10.1109/GOL49479.2020.9314733 . hal-03353086

\section{HAL Id: hal-03353086 \\ https://hal.science/hal-03353086}

Submitted on 23 Sep 2021

HAL is a multi-disciplinary open access archive for the deposit and dissemination of scientific research documents, whether they are published or not. The documents may come from teaching and research institutions in France or abroad, or from public or private research centers.
L'archive ouverte pluridisciplinaire HAL, est destinée au dépôt et à la diffusion de documents scientifiques de niveau recherche, publiés ou non, émanant des établissements d'enseignement et de recherche français ou étrangers, des laboratoires publics ou privés. 


\section{Studying the Rerouting of Empty Carriers during their Return Trips to Manage Rare Mobile Resources in a Physical Internet}

\author{
Moustafa Nakechbandi \\ LITIS, Le Havre University, \\ 5 rue $\mathrm{Ph}$. Lebon, Le Havre, France \\ moustafa.nakechbandi@univ-lehavre.fr
}

\begin{abstract}
To manage the unbalance between the needs in expensive containers (such as refrigerated containers or 'reefers') in some places, and the fact that the available empty containers of this kind are in another place, it is necessary to move these empty containers efficiently between places. In this paper, we use the empty carriers during their return trips after a delivery, to move the empty containers from the locations where they are, to the locations were they are needed. First, we use a method based on the Stepping Stone algorithm to compute a minimal cost list of moves in the associated transportation problem. Second, we use a heuristic to choose carriers during their return trips, and compute low cost possible path deviations that needed to accomplish these moves. A numerical example is presented at the end.
\end{abstract}

Keywords- Physical Internet, Transportation Problem, Vehicle Routing Problem with Backhauls, Shortest Path Problem.

\section{INTRODUCTION}

The concept of a Physical Internet (PI) is grounded on the idea that it is possible to manage the transportation of physical objects, such as containers and the goods inside, with the same principles used to manage data packets on the Internet. This may help to efficiently move these physical resources thanks to concepts and solutions developed for data networks, such as encapsulation, routing and resources sharing. It also leads to concepts such as smart modular containers and their physical routing ( $\pi$-containers, $\pi$-hubs...), and the management of carriers used to move them in a PI.

There are several reference models for data networks (the most famous being the OSI reference model and the TCP/IP reference model). For a Physical Internet, there are at least 2 different reference models: the OLI reference model of Montreuil [9] and the NOLI reference model [4, 5]. Table I below presents an overview of these reference models.

TABLE I.

AN OVERVIEW OF SOME REFERENCES MODELS FOR DATA AND LOGISTICS NETWORKS

\begin{tabular}{|c|c|c|c|}
\hline $\begin{array}{c}\mathrm{TCP} / \mathrm{IP} \\
\text { Layer Name } \\
\text { (Internet) }\end{array}$ & $\begin{array}{c}\text { OSI reference } \\
\text { Model } \\
\text { Layer Name } \\
\text { (electronic } \\
\text { network) }\end{array}$ & $\begin{array}{c}\text { OLI } \\
\text { Layer Name } \\
\text { (logistic } \\
\text { network) }\end{array}$ & $\begin{array}{c}\text { NOLI } \\
\text { Layer Name } \\
\text { (logistic } \\
\text { network) }\end{array}$ \\
\hline \multirow[t]{3}{*}{ Application } & 7. Application & $\begin{array}{ll}7 . & \text { Logistics } \\
\text { Web } & \end{array}$ & 7. Product \\
\hline & 6. Presentation & $\begin{array}{l}6 . \\
\text { Encapsulation }\end{array}$ & 6. Container \\
\hline & 5. Session & \multirow[t]{2}{*}{ 5. Shipping } & 5. Order \\
\hline Transport & 4. Transport & & 4. Transport \\
\hline Network & 3. Network & $\begin{array}{l}\text { 4. Routing } \\
\text { 3. Network }\end{array}$ & 3. Network \\
\hline $\begin{array}{l}\text { Network } \\
\text { Access }\end{array}$ & 2. Data Link & 2. Link & 2. Link \\
\hline Physical & 1. Physical & 1. Physical & $\begin{array}{l}\text { 1.Physical } \\
\text { Handling }\end{array}$ \\
\hline
\end{tabular}

\author{
Jean-Yves Colin \\ LITIS, Le Havre University, \\ 5 rue $\mathrm{Ph}$. Lebon,Le Havre, France \\ jean-yves.colin@univ-lehavre.fr
}

All these reference models are divided into several layers. Each layer is in charge of managing one part of this problem. The layers are stacked, and a layer $\mathrm{N}$ uses the services offered by the layer $\mathrm{N}-1$ below it, and offers services to the layer $\mathrm{N}+1$ above it. So each layer includes a list of the services it has, or just may offer. It also includes a description of each standard interface that must be used to utilize these services.

As one can see in Table I, the OSI, OLI and NOLI models all include seven layers. However, the 3, 4 and 5 OLI model layers are different from the 3,4 and 5 OSI model and NOLI model layers. We argue in [4] that the original 3, 4 and 5 layers in the OSI seem to be more appropriate, even for logistic networks, so we keep it this way in our NOLI model.

Furthermore, the OLI model manages all physical components in its Layer 1. We argue in [4] that, although this is also the case in the OSI model, this cannot be kept this way in logistic networks. Physical containers, for example, are physical objects, while their equivalents are additional electronic data in the OSI model. So in our model, containers appear as physical objects in Layer 6 in our NOLI model. Layer 1 in the NOLI model just defines and manages objects that are equivalent to physical objects in the OSI model.

For these reasons, we proposed our own NOLI reference model for logistics networks.

Fig. 1 below presents the 7 layers of the NOLI reference model, with some functionalities for each layer.

In our NOLI reference model, layer 6 defines the possible different types of physical objects that can be moved in this model, and describes all the different kind of $\pi$-containers that may be used to transport them. Layer 6 is also in charge of delivering empty $\pi$-containers to the places where they will be filled with physical goods, and to retrieve emptied $\pi$ containers once they reach the delivery place.

A more detailed explanation and discussion of the NOLI layers in Fig. 1 can be found in [4].

One aspect that is managed by layer 6 is the handling of the rare and expensive $\pi$-containers. These containers are more complex than basic containers, because they are used to move specific goods, or move some goods in specific situations. This includes refrigerated containers ('reefers') for moving frozen food or medicinal products.

Due to permanent or seasonal imbalances in trade, it is very common for these scarce and expensive containers to accumulate at delivery points (cities, ports, etc.) once emptied, and to be rarely available at the starting points (fruit and vegetable warehouses, pharmaceutical factories, etc.) to be filled. To ensure a good pooling of these resources (which is one of the goals of a Physical Internet), it is therefore necessary to reduce these imbalances by effectively 
transporting these scarce resources from the points where they are in excess, to the points where they are missing.
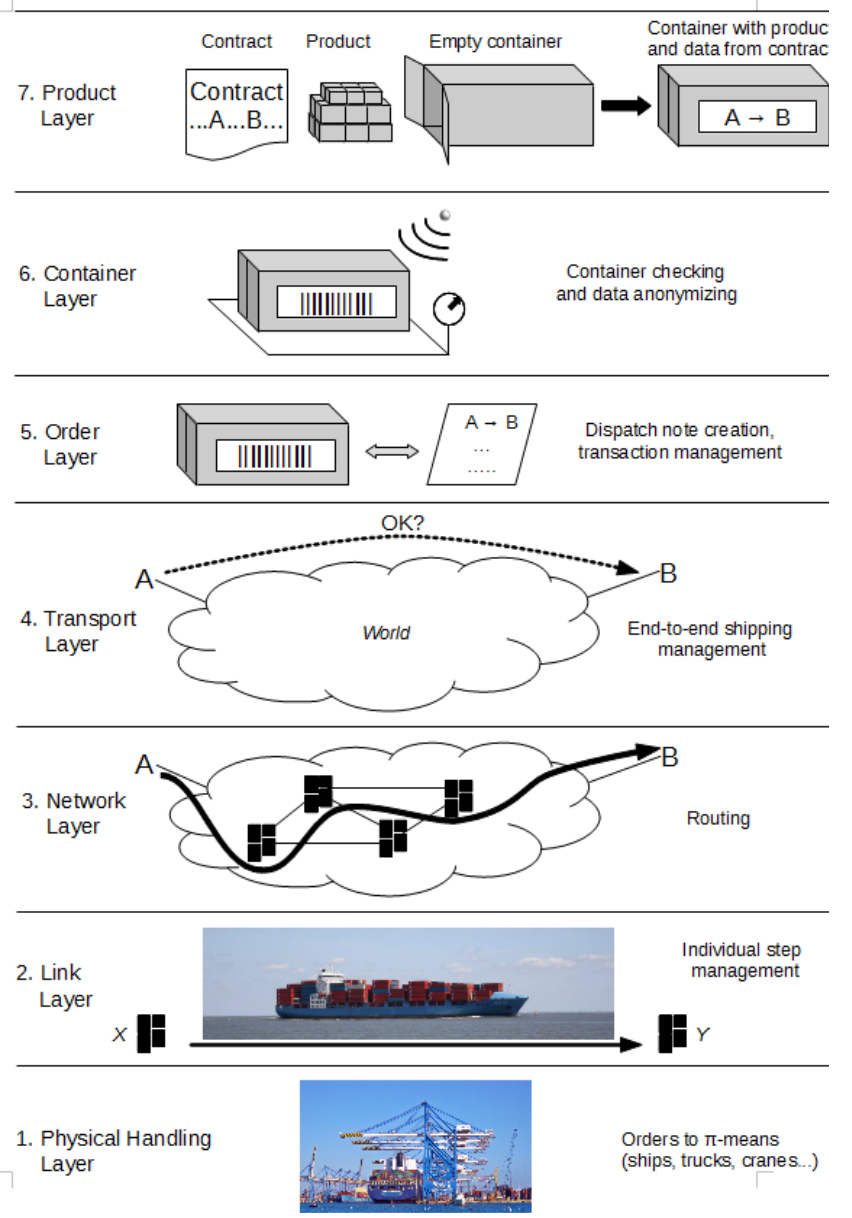

Fig. 1. Example of the structure of the NOLI reference model

A first solution is to manage a fleet of carriers dedicated to rebalancing. It is then necessary to find a sequence of stations (ports, etc.) visited by these carriers, and to move these resources to bring the system from the initial state $X$ to the desired state $\mathrm{Y}$, so that the total distance traveled in the sequence is as small as possible. This problem is a variant of vehicle routing problem $[3,8]$.

A second solution (also known as backhauling), studied in this article, is to try to use the return journeys of carriers (trucks, boats, etc.) which are often done empty or almost empty [1, 6, 13]. Examples of online marketplaces where senders of freights, and companies with empty carriers (returning or not) may directly search, meet and agree on a transportation fee include [14].

In this article, we formally study the rerouting of empty carriers, using finance to induce deviations in empty returning carriers, to have them fetch scarce empty resources or deposit them in locations outside the most often used roads. In a recent article [10] we analyzed the case where the trucks are initially in a single center. In the current article, the case where trucks are initially scattered in several centers is studied.

We propose an efficient algorithm to compute the lowest additional fee necessary to induce carriers to take and deposit rare resources, and even to deviate from their way to do so. Our solution is based on Warshall_Roy [11] for finding shortest paths. The result is used to get all deviation costs. The resulting transport problem is then solved using the method of Stepping Stone [2], which is a variant of the Simplex method.

\section{DEFINITION OF THE TRANSPORTATION PROBLEM}

In Internet, the electronic packets are created at the moment, and once arrived at their destination, they are erased. In a Physical Internet however, $\pi$-containers are physical objects: they are not created from scratch, and once arrived at destination, we cannot get rid of them so easily! and even more so for sophisticated containers (temperature-controlled containers or reefers ...) that are expensive and rare. In addition, it is very common for containers to accumulate in some places (cities, ports...), while they are missing at other places (factories, warehouse...) due to permanent or seasonal trade imbalances. In the NOLI model, this is supposed to be managed by layer 6 which (among other tasks) is in charge of managing the different types of containers and their availability.

The transport networks is modeled using a graph $G(V, U)$. $V$ is a set of locations (ports, $\pi$-hub...), representing production units (factories...) and consumption units (cities, factories...). $U$ is the set of physical paths between locations. The locations $\{v \in V\}$ are valued by a pair ( $x_{v}$ : offer, $y_{v}$ : request) of reefers. Each vertex $v \in V$ can receive, store and send these containers. The edges of $U$ are valued by a cost $\left\{d_{i, j} ;(i, j) \epsilon U\right\}$ which represents the distance between $i$ and $j$. Here is an example (Fig. 2):

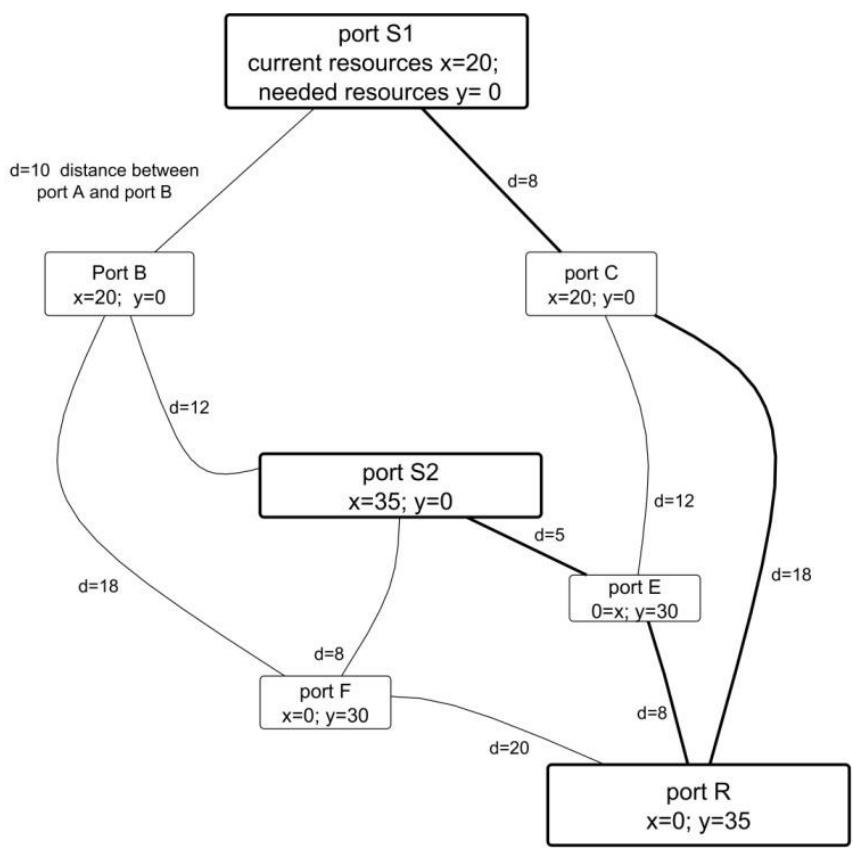

Fig. 2. Example of a transportation problem in which each vertex has a value $x$ of the current resources and a value $y$ of the resources needed. Each edge is valuated by its length $d$.

A set of trucks is present to transport goods from production centers to consumption centers. However, after having delivered the goods, these trucks are empty and must return towards their points of departure.

The idea is to take advantage of these return trips, sometimes by deviating them from their usual return path, to take empty containers from one vertex to drop them in another vertex where they are needed (Fig. 3).

The objective is to minimize the deviations of the trucks while the balancing of the resources between all ports (take excess containers and deposit them in the centers that need them). 


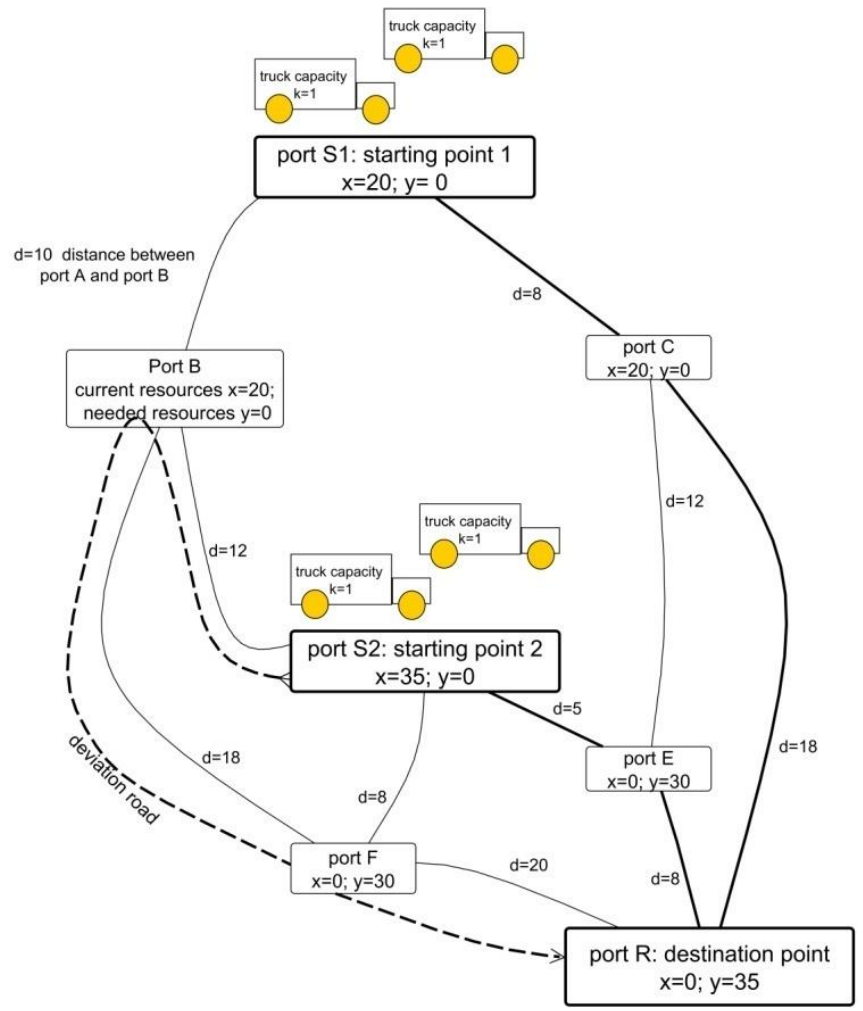

Fig. 3. Example of deviation: A vehicle which returns from $S 2$ to $R$ using the shortest path $(S 2, E, R)$ may follow another path (the dotted line) to fetch containers from $B$ to drop it $F$. The deviation cost $=12+18+20-13=37$.

In the following we assume that:

- The trucks are on two centers $S 1$ and $S 2$ and their destinations is a single center $R$. It is assumed that the number of trucks in $S 1$ is $t 1$, the number of trucks in $S 2$ is $t 2$.

- $n$ is the number of vertex (ports) in the problem.

- Let $i, j$ be two vertices. We note $P C C_{i j}$ the length of the shortest path to go from vertex $i$ to vertex $j$. Note that the Warshall-Roy algorithm [11] is a very efficient algorithm to compute the $P C C$ matrix.

- Deviation cost: This is the additional cost to send a truck from the starting vertex $S$ (S may be $S 1$ or $S 2$ ) to a vertex $X$ to serve a vertex $Y$. This cost is equal to (the cost to go from $S$ to $X)+($ the cost to go from $X$ to $Y)+($ the cost to go from $Y$ to $R$ ) - (the cost to go from $S$ to $R$ ) always by using the shortest way.

In the following we note : dev_cost $(S, X, Y, R))$ the deviation cost for a truck starting from $S \in\{S 1, S 2\}$, going to $X \epsilon V$ to serve $Y \epsilon V$ with end station R. We have:

$$
\begin{gathered}
d e v_{-} \operatorname{cost}(S, X, Y, R)= \\
P C C_{S X}+P C C_{X Y}+P C C_{Y R}-P C C_{S R}
\end{gathered}
$$

Example: In Fig. 3, let's apply the last expression (1) to compute the deviation cost that is indicated by the dotted line. We have:

$$
\begin{aligned}
& \operatorname{dev} \_\operatorname{cost}(S 2, B, F, R)= \\
& P C C_{S 2 B}+P C C_{B F}+P C C_{F R}-P C C_{S 2 R} \\
& =12+18+20-13=37
\end{aligned}
$$

- Let $M(S, R)$ be a matrix of dimension $n^{2}$, which corresponds to the deviation costs for a truck starting from $S$ going to $X$ to serve $Y$, going to the end station $R$. $(X, Y) \in V^{2}, V$ is the set of vertex in the graph $G(V, U)$. The elements of $M(S, R)$ will be noted $\left[m_{X, Y}(S, R)\right]$ with
$m_{X, Y}(S, R)=d e v \_\operatorname{cost}(S, X, Y, R) ; X, Y \epsilon V ; S \epsilon\{S 1, S 2\}$

- Definition: $\operatorname{Mmin}(S, R)$ is a matrix of dimension $n^{2}$ defined as follows :

$\operatorname{Mmin}(S, R)=\left[\operatorname{mmin}_{X, Y}(S, R)\right]$ with

$\operatorname{mmin}_{X, Y}(S, R)=\min \left\{m_{X, Y}(S 1, R), m_{X, Y}(S 2, R)\right\}$.

Thus, each element $(x, y)$ of $\operatorname{Mmin}(S, R)$ is inferior or equal to the element $(x, y)$ of $M(S \in\{S 1, S 2\}, R)$

\section{PROPOSED ALGORITHM}

\section{A. Algorithm}

In the following, we note:

$M 1=M(S 1, R), M 2=M(S 2, R)$, and $M 3=M \min (S, R)$.

That is, $M 1$ is the deviation costs for trucks starting from $S 1, M 2$ is the deviation costs for trucks starting from $S 2$, and $M 3$ is the minimal deviation costs when comparing $\mathrm{S} 1$ and $S 2$.

The proposed algorithm proceeds in four steps as follows:

- Step 1: The first step of the algorithm builds a table of the shortest paths between all pairs of nodes of graph, using the algorithm of Warshall-Roy [11].

- Step 2: The second step produces (based on the table constructed during step 1) two matrices of deviation costs: $M 1$ and $M 2$. It then builds matrix M3 (see definition above).

- Step 3: The third step uses the distance matrix M3 to formulate a classical transport problem between source nodes (supply) and destination (demand) nodes. This problem can be solved using the Stepping-Stone algorithm [2].

If the number of trucks available in $S 1$ and in $S 2$ is unlimited then end of algorithm

else continue with step 4:

- Step 4: This last step imposes an order on the routes to be completed, the least expensive first. Trucks are assigned to the routes in ascending order of deviation costs. In this step we use a classical list algorithm presented in the aria of scheduling problems with limited resources [7].

Note that if the number of available trucks in $S 1$ and in $S 2$ is unlimited, the solution found by the step 3 of the previous algorithm is an affectation with minimal transport cost. In our case, it is a solution with minimal deviation costs for the trucks.

\section{B. Detail of the algorithm with a numerical example}

We now detail the algorithm by applying it to the problem defined in the example of Fig. 3:

Step 1: Compute the table of the shortest paths between all pairs of vertices using the Warshall-Roy algorithm:

TABLE II. SHORTEST PATHS LENGTHS COMPUTED BY WARSHALL-ROY ALGORITHM

\begin{tabular}{|c|c|c|c|c|c|c|c|}
\hline & S1 & $\boldsymbol{B}$ & $\boldsymbol{C}$ & $\boldsymbol{S 2}$ & $\boldsymbol{E}$ & $\boldsymbol{F}$ & $\boldsymbol{R}$ \\
\hline S1 & 0 & 10 & 8 & 22 & 20 & 28 & 26 \\
\hline $\boldsymbol{B}$ & 10 & 0 & 18 & 12 & 17 & 18 & 25 \\
\hline $\boldsymbol{C}$ & 8 & 18 & 0 & 17 & 12 & 25 & 18 \\
\hline S2 & 22 & 12 & 17 & 0 & 5 & 8 & 13 \\
\hline $\boldsymbol{E}$ & 20 & 17 & 12 & 5 & 0 & 12 & 8 \\
\hline $\boldsymbol{F}$ & 28 & 18 & 25 & 8 & 12 & 0 & 20 \\
\hline
\end{tabular}




\begin{tabular}{|l|l|l|l|l|l|l|l|}
\hline $\boldsymbol{R}$ & 26 & 25 & 18 & 13 & 8 & 20 & 0 \\
\hline
\end{tabular}

TABLE III.

SUCCESSORS TABLE

\begin{tabular}{|c|c|c|c|c|c|c|c|}
\hline & S1 & $\boldsymbol{B}$ & $\boldsymbol{C}$ & S2 & $\boldsymbol{E}$ & $\boldsymbol{F}$ & $\boldsymbol{R}$ \\
\hline S1 & $S 1$ & $B$ & $C$ & $B$ & $C$ & $B$ & $C$ \\
\hline $\boldsymbol{B}$ & $S 1$ & $B$ & $S 1$ & $S 2$ & $S 2$ & $F$ & $S 2$ \\
\hline $\boldsymbol{C}$ & $S 1$ & $S 1$ & $C$ & $E$ & $E$ & $E$ & $R$ \\
\hline S2 & $B$ & $B$ & $E$ & $S 2$ & $E$ & $F$ & $1 E$ \\
\hline $\boldsymbol{E}$ & $C$ & $S 2$ & $C$ & $S 2$ & $E$ & $S 2$ & $R$ \\
\hline $\boldsymbol{F}$ & $B$ & $B$ & $S 2$ & $S 2$ & $S 2$ & $F$ & $R$ \\
\hline $\boldsymbol{R}$ & $C$ & $E$ & $C$ & $E$ & $E$ & $F$ & $R$ \\
\hline
\end{tabular}

This last Table III allows us to build shortest paths between all the vertices. For example, in the path from $S 1$ to $S 2$, the successor of $S 1$ is $B$ and the successor of $B$ is $S 2$, so the shortest path will be $(S 1, B, S 2)$.

Step 2: Compute $M 1$ and $M 2$ that contain the deviation costs between all the vertices from $S 1$ and from $S 2$ using the expression given by equation (1).

TABLE IV. MATRIX $M 1$ : THE COST OF DEVIATIONS RELATING TO DEPARTURE FROM $S I$

\begin{tabular}{|c|c|c|c|c|c|c|c|}
\hline & $S 1$ & $B$ & $C$ & $S 2$ & $E$ & $F$ & $R$ \\
\hline$S 1$ & 0 & 9 & 0 & 9 & 2 & 22 & 0 \\
\hline$B$ & 10 & 0 & 10 & 9 & 9 & 22 & 9 \\
\hline$C$ & 8 & 17 & 0 & 9 & 2 & 27 & 0 \\
\hline$S 2$ & 22 & 33 & 31 & 0 & 9 & 24 & 9 \\
\hline$E$ & 40 & 36 & 24 & 12 & 0 & 26 & 2 \\
\hline$F$ & 56 & 45 & 55 & 23 & 23 & 0 & 22 \\
\hline$R$ & 52 & 50 & 36 & 26 & 16 & 40 & 0 \\
\hline
\end{tabular}

TABLE V.

MATRIX M2: THE COST OF DEVIATIONS RELATING TO DEPARTURE FROM $S 2$

\begin{tabular}{|c|c|c|c|c|c|c|c|}
\hline & S1 & $\boldsymbol{B}$ & $\boldsymbol{C}$ & $\boldsymbol{S 2}$ & $\boldsymbol{E}$ & $\boldsymbol{F}$ & $\boldsymbol{R}$ \\
\hline$S 1$ & 0 & 34 & 30 & 44 & 37 & 57 & 35 \\
\hline$B$ & 35 & 0 & 35 & 24 & 24 & $\mathbf{3 7}$ & 24 \\
\hline$C$ & 38 & 47 & 0 & 34 & 24 & 49 & 22 \\
\hline$S 2$ & 35 & 24 & 22 & 0 & 0 & 15 & 0 \\
\hline$E$ & 38 & 34 & 22 & 5 & 0 & 25 & 0 \\
\hline$F$ & 49 & 38 & 48 & 16 & 16 & 0 & 16 \\
\hline$R$ & 52 & 50 & 36 & 26 & 16 & 40 & 0 \\
\hline
\end{tabular}

Then deduce $M 3: m 3_{i j}=\min \left(m 1_{i j}, m 2_{i j}\right) ; i, j \epsilon V:$

TABLE VI. MATRIX $M 3=M I N(M 1, M 2)$. INSIDE S1 OR S2 INDICATES THE STARTING POINT OF TRUCKS.

\begin{tabular}{|c|c|c|c|c|c|c|c|}
\hline & S1 & $\boldsymbol{B}$ & $\boldsymbol{C}$ & $\boldsymbol{S 2}$ & $\boldsymbol{E}$ & $\boldsymbol{F}$ & $\boldsymbol{R}$ \\
\hline S1 & $0:$ & $9: S 1$ & $0: S 1$ & $9: S 1$ & $2: S 1$ & $22: S 1$ & $0: S 1$ \\
\hline $\boldsymbol{B}$ & $10: S 1$ & 0 & $10: S 1$ & $9: S 1$ & $9: S 1$ & $22: S 1$ & $9: S 1$ \\
\hline $\boldsymbol{C}$ & $8: S 1$ & $17:$ & 0 & $9: S 1$ & $\mathbf{2}:$ S1 & $27: S 1$ & $0: S 1$ \\
& & $S 1$ & & & & & \\
\hline S2 & $22: S 1$ & $24: S 2$ & $22: S 2$ & 0 & $0: S 2$ & $15: S 2$ & $0: S 2$ \\
\hline $\boldsymbol{E}$ & $35: S 2$ & $24: S 2$ & $22: S 2$ & $0: S 2$ & 0 & $25: S 2$ & $0: S 2$ \\
\hline $\boldsymbol{F}$ & $49: S 2$ & $38: S 2$ & $48: S 2$ & $16: S 2$ & $16: S 2$ & 0 & $16: S 2$ \\
\hline $\boldsymbol{R}$ & $52:$ & $50:$ & $36:$ & $26:$ & $16:$ & $40:$ & 0 \\
& $S 1$ & $S 1$ & $S 1$ & $S 1$ & $S 1$ & $S 1$ & \\
\hline
\end{tabular}

From the global matrix, we extract the sub matrix (Table VII) that only gives the deviations costs from sites with available empty reefers, to sites that need empty reefers. Sites that do not have and do not need empty reefers are removed.

TABLE VII. SUB-MATRIX EXTRACTED FROM $M 3$

\begin{tabular}{|c|c|c|c|}
\hline & $\boldsymbol{E}$ & $\boldsymbol{F}$ & $\boldsymbol{R}$ \\
\hline S1 & $9: S 1$ & $22: S 1$ & $0: S 1$ \\
\hline $\boldsymbol{B}$ & $9: S 1$ & $12: S 1$ & $9: S 1$ \\
\hline $\boldsymbol{C}$ & $2: S 1$ & $29: S 1$ & $0: S 1$ \\
\hline S2 & $0: S 2$ & $15: S 2$ & $0: S 2$ \\
\hline
\end{tabular}

Step 3: Use the Stepping-Stone method to solve the following transport problem:

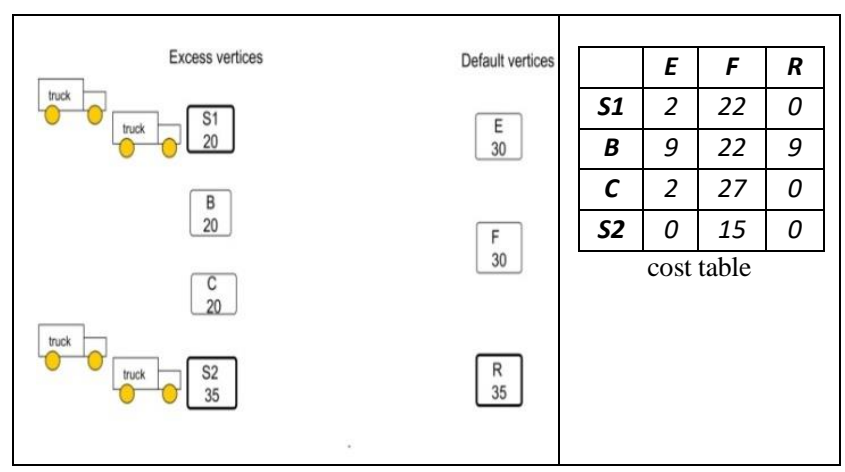

Fig. 4. Transport problem from example1. $S 1, S 2$ are the starting trucks locations. $R$ is the destination trucks location.

This gives the following affectation solution:

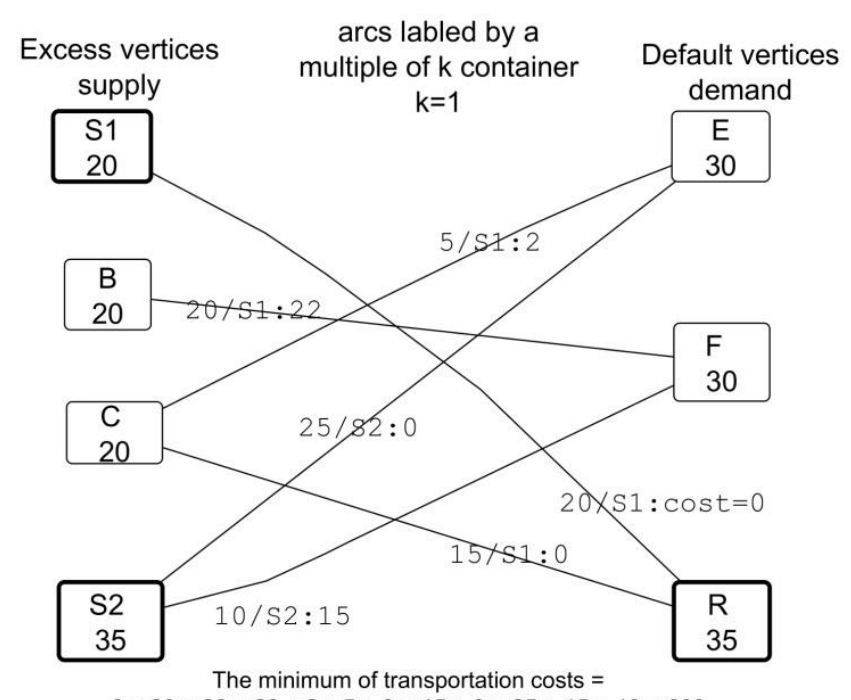
$0 \times 20+22 \times 20+2 \times 5+0 \times 15+0 \times 25+15 \times 10=600$

Fig. 5. The solution given by the Stepping-Stone method. For example the value $5 / \mathrm{S} 1: 2$ associated to the arc $(\mathrm{C}, \mathrm{E})$ means that 5 containers will be sent from $\mathrm{C}$ to $\mathrm{E}$ by trucks coming from $\mathrm{S} 1$. The deviation cost of this transportation is 2 .

This solution assumes that the number of trucks returning empty from $S 1$ to $R$ and from $S 2$ to $R$ is unlimited.

Here to satisfy all requests we need $t l=60$ trucks in $S 1$ and $t 2=35$ trucks in $S 2$. The minimum transportation cost is 600 (see Fig. 5), in this solution:

- 20 trucks (number 1-20 in $S 1$ ) bring 20 containers from $S 1$ to $R$ passing through $C$ as indicated by the successors table (Table III).

- 20 trucks (number 21-40 in S1) coming empty from $S 1$ to B, bring 20 containers from $B$ to $F$ and then take the road directly towards the final destination $R$. 
- 5 trucks (number 41-45 in $S 1$ ) leave empty from $S 1$ to $C$, bring back 5 containers from $C$ to $E$ then take the road directly towards the final destination $R$.

- 15 trucks (number 45-60 in $S 1$ ) coming empty of $S 1$ to $C$ bring 15 containers from $C$ to $R$ who is the final destination.

- 25 trucks (number 1-25 who are now in $S 2$ ) leaving $S 2$ bring 25 containers from $S 2$ to $E$ and then take the road directly to the final destination $R$.

- 10 trucks (number 26-35 in $S 2$ ) leaving $S 2$ bring 10 containers from $S 2$ to $F$ and then take the road directly to the final destination $R$.

If the number of trucks is limited, then we must try to serve the maximum demand with the minimum of costs. Let $p=45$ be the number of trucks in $S 1$, and $q=30$ be the number of trucks in $S 2$. We have $p<t 1$ and $q<t 2$ then we go to additional step 4 :

Step 4: The Fig. 5 gives the set of affectation: $\{(S 1, R$, 20/S1), (B,F, 20/S1), (C,E, 5/S1), (C,R,15/S1), (S2,E, 25/S2), $(S 2, F, 10 / S 2)\}$, with $(\mathrm{P}, \mathrm{Q}, \mathrm{C} / \mathrm{S})$ meaning than C Containers are taken in site $\mathrm{P}$ and dropped at site $\mathrm{Q}$ by trucks returning empty from site $S \epsilon\{S 1, S 2\}$. This may imply a deviation.

If this set is sorted in ascending order according to the costs of the trajectory deviations (Table VII), we have the following priority list: \{ ((S1,R),20/S1:0), ((C,R),15/S1:0), ((S2,E),25/S2:0), ((C,E),5/S1:2), ((B,F),20/S1:22), ((S2,F),10/S2:15) \}. The number added at the end of each affectation is the additional cost due to the deviation, if any. Using this list:

- The first element in this list is $(S 1, R), 20 / S 1: 0)$, so the first routes will be $(\mathrm{S} 1, \mathrm{R})$ in which 20 trucks take 20 containers from $\mathrm{S} 1$ and transported directly to $\mathrm{R}$, the trucks remaining in $S I=45-20=25$.

- The following element in the list is $((C, R), 15 / S 1: 0)$, so second deviation route is $(S 1, C, R)$ to take 15 containers from $C$, to serve $R$. Thus $R$ satisfies all its demands (20+ $15=35)$. There are now $10=(25-15)$ empty trucks remaining in S1.

- The next element in the list is $((S 2, E), 25 / S 2: 0)$, so the following routes is $(S 2, E, R)$ to take 25 containers from $\mathrm{S} 2$ to serve E. Now only $5=(30-25)$ trucks remaining in S2.

- The next element in the list is $((C, E), 5 / S 1: 2)$, so the following routes is $(S 1, C, E, R)$ to take 5 containers from $C$ to serve $E$ (deviation cost $=2$ ). Now only $5=(10-5)$ trucks remaining in $S 1$.

- The following element in the list is $((B, F), 20 / S 1: 22)$, so the following routes is $(S 1, B, F, R)$ to take 5 containers from $B$ to serve $F$. No trucks remaining in $S 1$.

- The following available element in the list is $((S 2, F), 10 / S 2: 15)$, so the following routes will be take 5 trucs which stay in $S 2$ to take 5 from $S 2$ to serve $F$. No trucks remaining in $S 2$.

At the end of this step, 15 containers remain in $B$ and 5 containers remain in $S 2$.

\section{Analysis of the algorithm}

For a problem of dimension $n$, the algorithm of Warshall is an algorithm of complexity $o\left(n^{3}\right)$.
Stepping-Stone is a variant of the Simplex method, although the practical efficiency is remarkable with a very fast convergence, the number of iterations of the simplex is not polynomial: there are pathological instances proving this. If we assume that the Simplex method requires $m$ iterations, then the complexity of the simplex is $o\left(n^{2} m\right)$.

Hence for the first three steps of our algorithm the complexity of our algorithm is $o\left(n^{3}\right)+o\left(n^{2} m\right)$. The step 4 is a heuristic whose cost of calculation can be neglected.

If the number of trucks available is unlimited, and the offers are equal to the requests: $\sum_{v \in V} x_{v}=\sum_{v \in V} y_{v}$ then all the transports calculated in step 3 can be done, and the order of the trips will not be important. The proposed solution up to step 3 (see Fig. 5) is an optimal solution.

\section{DISCUSSION}

This article concludes with a number of remarks:

- if we use step 4 because there is a limited number of returning empty trucks, one can notice that it is necessary to pay attention to the possible cases of starvation, because some nodes far removed from the classic routes may never be served. A possible idea then is to dynamic lower the deviation costs with time, so that nodes that have not be considered for a long time will eventually have the highest priorities.

- It can also be noted that only direct links are considered here. It would be possible to study the possibility of using partial steps to gradually bring resources closer to the places in need. Heuristics, such as ant algorithms, can be considered.

- The assumption that there are only two departure centers of the trucks $S 1, S 2$ and only one destination trucks center which is used in the example illustrating the details of the algorithm, does not limit the application of our algorithm. Indeed, our algorithm can be applied to 3 or more starting centers. The same can be said for the number of destination trucks centers.

- The Stepping-Stone [2] method is very old, so newer versions that are more efficient can be used [12].

\section{CONCLUSIONS AND FUTURE WORK}

In this article, we tried to use the return trips of carriers (trucks, boats, etc.), which are often done empty or almost empty, to re-balance the scarce and expensive resources present in the logistics network, with the aim of improving the pooling of these resources in the context of a Physical Internet. Deviations are allowed.

In our problem, the implicit assumption that a truck will do only one 'load-unload' operation during its return trip is restrictive. In our future work, we intend to consider solutions that include several deviations.

Also, the arcs of the graph are valuated with fixed transport costs. So it may be more realistic to introduce some variable costs depending on the transport environment (congested road, or very long deviation route which imply nonlinear transport costs, or time dependent costs...). In our future work, we intend to study this coupling between dynamic graphs and transport problems in this context.

\section{ACKNOWLEDGMENT}


This work is supported by the Normandy Region, CLASS 2 Project "Logistic Corridors: Applications to the Seine Valley and Its Environment", France.

\section{REFERENCES}

[1] Anily, S. The Vehicle Routing Problem with Delivery and Backhaul Options. Naval Research Logistics 43:415-434, (1996). .

[2] A. Charnes, A. W.W. Cooper, "The Stepping Stone Method of Explaining Linear, in Transportation Problems", Management Science, Oct. 1954, pp. 49-69, (1954).

[3] J.-Y. Colin, M. Nakechbandi, H. Mathieu,"Management of mobile resources in Physical Internet logistic models", , ICALT 2015, 4th IEEE Int. Conf. on Advanced Logistics \& Transport, Valenciennes, France, (2015).

[4] Colin, J.-Y., Mathieu, H., Nakechbandi, M. "A Proposal for an Open Logistics Interconnection Reference Model for a Physical Internet", The 3rd International IEEE Conference on Logistics Operations Management(GOL16), Fez, Marocco (2016).

[5] J.-Y. Colin, H. Mathieu, M. Nakechbandi, "NOLI A Proposal for an Open Logistics Interconnection Reference Model for a Physical Interne", IPIC 2017, 4th International Physical Internet Conference. (2017).
[6] M. Goetschalckx, C. Jacobs-Blecha, "The vehicle routing problem with backhauls: Properties and solution algorithms", Technical Report MHRC-TR-88-13, Georgia Institute of Technology, (1993)

[7] Graham, R.L.: Bounds for certain multiprocessing anomalies. Bell Syst. Techn. J. 45, 1563-1581 (1966).

[8] Meunier F., Un problème de tournée inspiré par la régulation des systèmes de transport en libre-service, journée JFRO, 3-2012, Paris (2012).

[9] B. Montreuil, "Physical Internet manifesto: globally transforming the way physical objects are handled, moved, stored, realized, supplied and used" Technical Report, (2009).

[10] M. Nakechbandi, J.-Y. Colin, H. Mathieu, "La gestion des ressources mobiles rares dans un Internet Physique sans ressources dédiées", Logistiqua, Paris, France, 12-14 juin 2019 (2019).

[11] Roy B. Algebre moderne et theorie des graphes, Dunod (1970).

[12] S. Vimala1, K. Thiagarajan and A. Amaravathy, "OFSTF Method - An Optimal Solution for Transportation Problem", Indian Journal of Science and Technology, Vol 9(48), (2016).

[13] Papadimitriou, C.H., and Steiglitz, K., Combinarorial Optimization Algorithms and Complexity, Chap. 7, Prentice Hall, Inc., Englewood Cliffs, NJ, (1982)

[14] Internet References :

- Freight exchange: https://teleroute.com

- Exchange platform: https://www.freights.online/ 